\title{
Thank You
}

Leslie C. Dort, DDS, Diplomate, ABDSM, Editor-in-Chief Journal of Dental Sleep Medicine

Calgary, Alberta, Canada

My decision to step down as the Editor-in-Chief of the Journal of Dental Sleep Medicine has been bittersweet. My work with the journal began over 5 years ago when I was honored to be appointed the first Editor-in-Chief. It was a huge but satisfying challenge to launch the first peer reviewed journal devoted to dental sleep medicine. There are many people I must thank.

The managing editorial staff, in particular: Rosanne Money and Jon Wending, have been invaluable with their patient and professional guidance. I applaud the authors who have risked publishing the efforts of their difficult and meticulous research in a new journal. Thank you to the clinicians who when asked, stepped out of their comfort zones to author the clinically important case reports in the journal. Many reviewers worldwide have been generous with their time and expertise. The editors and editorial board have supported the growth of the journal. I would particularly like to thank Drs. Rose Sheats, Gilles Lavigne and Jean-Francois Masse. They are all very busy people who always found the time to do the work asked of them for the Journal of Dental Sleep Medicine.
The next part of the journey for the Journal of Dental Sleep Medicine will be guided by new Editor-in-Chief: Dr. JeanFrancois Masse. The journal is in good hands.

Thank you all.

\section{CITATION}

Dort LC. Thank You. Journal of Dental Sleep Medicine. 2018;5(1):3.

\section{SUBMISSION \& CORRESPONDENCE INFORMATION}

Submitted for publication December 8, 2017

Submitted in final revised form December 8, 2017

Accepted for publication December 8, 2017

Address correspondence to: Leslie C. Dort, DDS, 1016-68th Ave SW, Suite 150, Calgary, AB T2V 4J2, Canada; Tel: (403) 202-4905; Fax:

(403)202-0266; Email: lcdort@gmail.com 